\title{
Parotiditis Crónica Recurrente o Síndrome de Sjögren Primario Juvenil? Reporte de un Caso
}

\author{
NEIRA CHAPARRO G. ${ }^{1}$, PAOLA MÉNDEZ V. ${ }^{2}$, \\ CAROLINA RODRÍGUEZ R. ${ }^{2}$, THAIS ROJAS-MORALES ${ }^{3}$ \\ 1. Odontóloga, MgSc Medicina Oral. Instituto de Investigaciones. Facultad de Odontología. Universidad de Zulia. \\ Hospital Universitario de Maracaibo. Maracaibo, Venezuela. \\ 2. Odontóloga, Auxiliar de Investigación. Instituto de Investigaciones. Facultad de Odontología. Universidad de Zulia. \\ 3. Odontóloga, MgSc Odontopediatría. Instituto de Investigaciones. Facultad de Odontología. Universidad de Zulia.
}

\begin{abstract}
Chronic Recurrent Parotiditis or Juvenile Primary Sjögren? A Case Report

Introduction: Chronic Recurrent Parotiditis is a recurrent swelling of the parotid gland, of multiple etiology. In some cases it may be an early manifestation of Sjögren's syndrome. Objective: A comparison of both diseases, in light of the clinical, radiological, histological and laboratory findings in a patient suffering from a chronic recurrent parotiditis suggestive of Sjögren's syndrome. Case Report: A 14 years old girl, seen in Oral Maxillary Medicine consultation at "Hospital Universitario de Maracaibo", for a year's history of multiple episodes of parotid swelling. Glandular involvement was confirmed clinically. While dental cavities and thick saliva were observed, the absence of oral dryness and ocular manifestations resulted in a diagnosis of Chronic Recurrent Parotitis at the time. Due to multiple recurrent dental cavities, high recurrence of the swelling episodes, and poor response to treatment, Sjögren's syndrome was suspected. Lower lip minor salivary gland biopsy, specific antibodies, sialometry and Schirmer's test were requested, finding enough positive criteria for the diagnosis of Sjögren's syndrome. Conclusions: Among children and teenagers with CRP with treatment failure, the presence of Sjögren's syndrome must be evaluated, even in the absence of oral and ocular symptoms.

(Key words: Recurrent parotitis, Sjögren, autoimmunity).

Rev Chil Pediatr 2009; 80 (4): 361-366
\end{abstract}

\section{RESUMEN}

Introducción: La parotiditis crónica recurrente es una inflamación recidivante de la glándula, producida por diversos factores, sin embargo, ésta en algunos casos puede presentarse como primera manifestación del síndrome de Sjögren. Objetivo: Describir la relación existente entre los signos y síntomas de ambas patologías, evaluando los hallazgos clínicos, radiográficos, histológicos y de laboratorio encontrados en un paciente con antecedentes de parotiditis crónica recurrente y criterios positivos para Síndrome de Sjögren. Presentación del caso: Paciente femenino de 14 años de edad, atendida en la consulta de

Trabajo recibido el 04 de julio de 2008, devuelto para corregir el 15 de noviembre de 2008, segunda versión el 03 de marzo de 2009, aceptado para publicación el 11 de mayo de 2009.

Correspondencia a:

Dra. Neira Chaparro G.

E-mail: neirachaparro61@gmail.com 
Medicina Bucal del Hospital Universitario de Maracaibo por presentar múltiples aumentos de volumen parotídeo de 1 año de evolución. Clínicamente se confirmó los cambios glandulares, observándose además caries y salivación espesa, sin sequedad bucal ni molestias oculares, llegando al diagnóstico de Parotiditis Crónica Recurrente. Ante las múltiples caries avanzadas, la marcada recurrencia de los episodios inflamatorios y respuesta inadecuada al tratamiento, se solicitó biopsia de glándula salival menor de labio inferior, anticuerpos específicos para el síndrome de Sjögren, sialometría y test de Schirmer, encontrando criterios positivos suficientes para diagnosticar este Síndrome. Conclusión: En pacientes niños y adolescentes con PCR en los cuales a pesar del tratamiento indicado no se logre prolongar el tiempo entre las recurrencias ni disminuir el aumento de tamaño de la glándula satisfactoriamente, debe ser evaluada la presencia del Síndrome de Sjögren, aún en ausencia de síntomas oculares y bucales.

(Palabras clave: Sjögren, parotiditis recurrente, autoinmune).

Rev Chil Pediatr 2009; 80 (4): 361-366

\section{Introducción}

La parotiditis crónica recurrente (PCR) y el Síndrome de Sjögren (SS), producen afectación de las glándulas salivales, especialmente a nivel de parótida y ambas son de etiología desconoci$\mathrm{da}^{1-6}$. La PCR se ha catalogado como una enfermedad inflamatoria crónica cuya mayor incidencia se encuentra entre los 3 y 6 años de edad $^{1,2,4-8}$ y tiende a remitir en la pubertad ${ }^{1,4-9}$; sin embargo, también se ha observado en la edad adulta, pero con mucha menos frecuencia. En cuanto al sexo, la mayoría de los autores coinciden en que la diferencia porcentual entre ambos es mínima y no muy relevante ${ }^{2,4,7-9}$. Por otro lado, el SS se ha definido como una enfermedad crónica autoinmune ${ }^{10-16}$ que afecta con mayor frecuencia a adultos de sexo femenino entre la cuarta y sexta década de la vida, constituyendo las mujeres el $90 \%$ de los pacientes diagnosticados ${ }^{11,12,14,17}$.

El SS puede ocurrir de dos formas: primario, cuando las manifestaciones clínicas se limitan a las glándulas exocrinas; y secundario, en presencia de otra enfermedad autoinmune ${ }^{10,12,17}$. Para el SS no existe una prueba diagnóstica simple y directa, por lo que internacionalmente se utilizan los criterios propuestos por la American-European Consensus Group para establecer el diagnóstico ${ }^{11}$. La presencia de este síndrome en niños no es común y es frecuentemente una condición no diagnosticada debido a la limitación existente en la aplicabilidad de los criterios diagnósticos en edades tempranas ${ }^{12,14,15}$.

Clínicamente la PCR se manifiesta como una inflamación recidivante de la glándula parótida, uni o bilateral, con dos o más episodios inflamatorios de dolor e intensidad variables, separados por intervalos de tiempo asintomáti$\cos ^{2,4,5,7-9,18-20}$. Durante un episodio agudo, se observa extraoralmente cierta asimetría facial causada por el aumento de la zona glandular, la palpación revela sensibilidad e induración en la glándula, de la cual se puede seguir su contorno anatómico ${ }^{6,20}$. La superficie de la piel que cubre la zona puede aparecer normal o ligeramente inflamada y enrojecida; esta inflamación puede persistir por 24 ó 48 horas, 1 ó 2 semanas o meses, como se ha observado en algunos pacientes ${ }^{2,5-7,9,20}$. Intraoralmente se puede observar el conducto de Stenon inflamado o enrojecido; al ser ordeñada la glándula se puede observar una marcada disminución del flujo salival y un drenaje de saliva viscosa con o sin floculaciones, las cuales representan la presencia de secreción condensada, epitelio descamado del conducto, elevados niveles de proteínas salivales y plasmáticas, células inflamatorias e incluso pus cuando la infección se convierte en una manifestación secundaria. Es común encontrar linfoadenopatías cervicales, malestar y un bajo grado de fiebre $7,9,19,20$.

En pacientes con SS los episodios inflamatorios pueden presentarse de manera similar, el aumento recurrente de las parótidas puede ser uno de los primeros signos y síntomas de la enfermedad en la niñez, seguido de xeroftalmia o queratoconjuntivitis seca y xerostomía $3,12,15,17,21$. La xeroftalmia se manifiesta por una serie de síntomas descritos como prurito, sensación de cuerpo extraño, signos de dismi- 
nución del lagrimeo, hiperemia de la conjuntiva $\mathrm{y}$ gran fotosensibilidad ${ }^{10,11,13,17,22}$. El principal síntoma oral es la xerostomía o sequedad bucal, la que ocasiona problemas funcionales, mayor susceptibilidad a las caries, enfermedad periodontal y predisposición a las infecciones orales, especialmente candidiasis ${ }^{10,11,22}$. Puede presentarse en ocasiones una tumefacción o hipertrofia de las glándulas salivales, de carácter crónico y progresivo, generalmente a nivel de las parótidas de forma unilateral o bilateral, adoptando una consistencia firme a la palpación, poco o nada dolorosa ${ }^{22}$. También pueden quejarse de sequedad en otras áreas como nariz, garganta, vagina, recto y piel ${ }^{10-12}$.

Histológicamente, ambas alteraciones presentan infiltración linfocitaria que se inicia en la zona periductal y termina presentando reducción progresiva del parénquima; estos hallazgos parecen manifestarse de manera más intensa en el SS que en la PCR. Otras semejanzas entre estas dos entidades aparecen también en estudios de imagen, reportándose para ambas, múltiples áreas hiperecoicas, hipoecoicas y áreas punteadas o globulares; sin embargo, en la PCR se reporta un aspecto de cuentas de un rosario o de salchichas en los conductos ${ }^{4,7}$ que parece no presentarse en el $\mathrm{SS}^{23}$.

En el presente estudio se pretende describir la relación existente entre los signos y síntomas de ambas patologías, evaluando los hallazgos clínicos, radiográficos, histológicos y de laboratorio encontrados en un paciente con antecedentes de parotiditis crónica recurrente y criterios positivos para Síndrome de Sjögren.

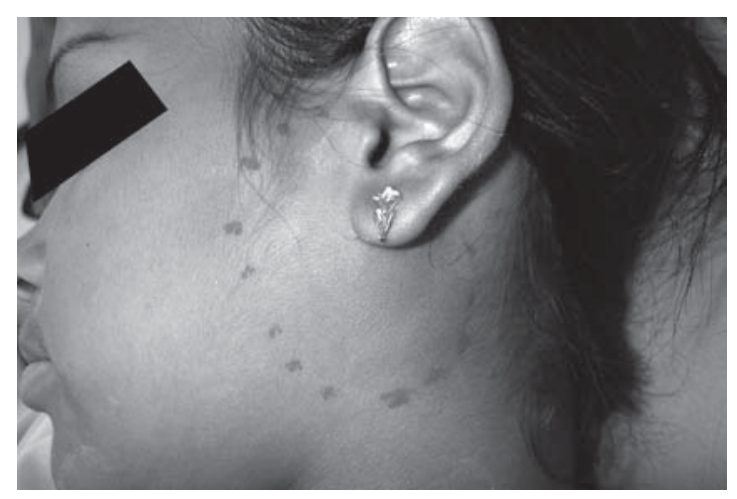

Figura 1. Inflamación parotídea con presencia de rubor, calor y dolor.

\section{Caso Clínico}

Paciente femenino de 14 años de edad, con antecedentes de amigdalitis, otitis, asma, alergias y prolapso de la válvula mitral, que acudió a la consulta de Medicina Bucal del Hospital Universitario de Maracaibo, referida del Servicio de Infectología del mismo hospital, por presentar múltiples episodios de inflamación parotídea bilateral de 6 meses de evolución, precedidos generalmente por otitis o gripe y separados por intervalos asintomáticos de 1 a 2 meses.

Extraoralmente se observó asimetría facial causada por aumento moderado de ambas parótidas, siendo el lado izquierdo el más afectado, con aproximadamente $5 \mathrm{~cm}$, en su diámetro mayor, acompañado de induración, rubor, calor, y ligero dolor a la palpación (figura 1). El examen clínico intraoral reveló múltiples caries e irritantes locales (figura 2), con salivación espesa y floculaciones al ordeño de la glándula (figura 3); sin embargo, la mucosa se observó húmeda y brillante. Se indicaron estudios hematológicos, serológicos, inmunológicos y resonancia magnética, lo que permitió identificar niveles de hemoglobina ligeramente por debajo de los valores normales, serología positiva para Citomegalovirus ( $\mathrm{IgG})$, y niveles elevados de Inmunoglobulinas G y E (3 220 mg/dl y 714 ug/ dl respectivamente). Tanto la ecografía parotídea aportada por el paciente como la Resonancia Magnética, revelaron proceso inflamatorio inespecífico tipo sialectasia globulosa, con aumento de volumen principalmente del lado iz-

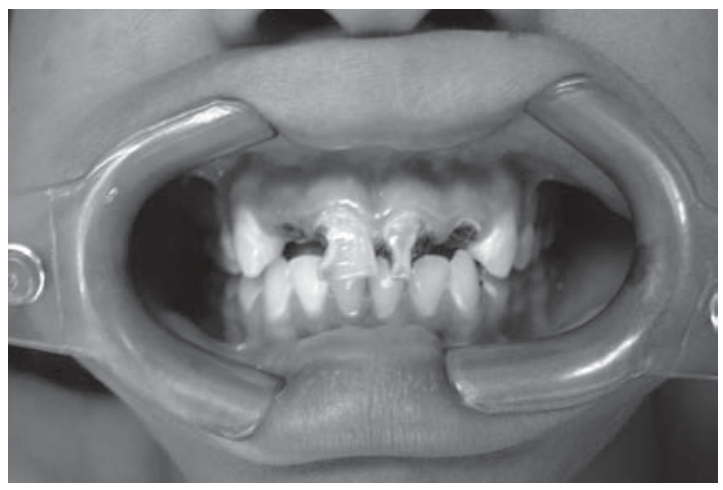

Figura 2. Presencia de múltiples caries avanzadas. 


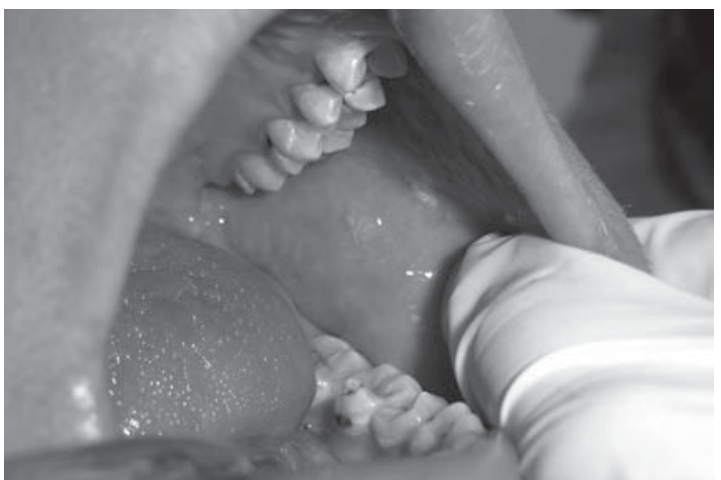

Figura 3. Drenaje de floculaciones.

quierdo y dilataciones ductales en ambas glándulas. En base a estos hallazgos se llegó al diagnóstico de Parotiditis Crónica Recurrente.

Al momento de presentarse los episodios agudos de parotiditis, se instauró un tratamiento con AINES vía oral y tópicos, además de abundante hidratación; la antibioticoterapia fue administrada sólo en un episodio en el que se observó saliva purulenta. En vista de la marcada recurrencia y la persistencia de los signos y síntomas a pesar del tratamiento aplicado, se decidió realizar instilaciones intraductales a través del conducto de Stenon con solución salina semanalmente, sin obtener resultados positivos, procediéndose entonces, a pesar de no referir xerostomía ni trastornos oculares, a solicitar otros exámenes complementarios que permitieran la reevaluación del paciente, como anticuerpos antinucleares (ANA), Factor Reumatoide (FR) y anticuerpos específicos para el Síndrome de Sjögren, como el SSA o Anti-Ro y el SSB o Anti-La, los cuales resultaron positivos. Adicionalmente, se indicó biopsia de glándulas salivales menores en labio inferior, la cual reveló un abundante infiltrado linfocitario (figura 4), mientras que la sialometría evidenció valores inferiores a los normales en saliva total no estimulada $(0,2 \mathrm{ml} / 15 \mathrm{~min})$ y estimulada $(3,5$ $\mathrm{ml} / 15 \mathrm{~min}$ ) así como también en saliva parotídea no estimulada $(0 \mathrm{ml} / 15 \mathrm{~min})$ y estimulada $(0,4$ $\mathrm{ml} / 15 \mathrm{~min}$ ) (figura 5). Posteriormente se realizó interconsulta con Oftalmología, quienes informaron queratitis, importante resequedad en ambos ojos y Test de Schirmer positivo (figura 6), prescribiéndole lágrimas artificiales. Ante
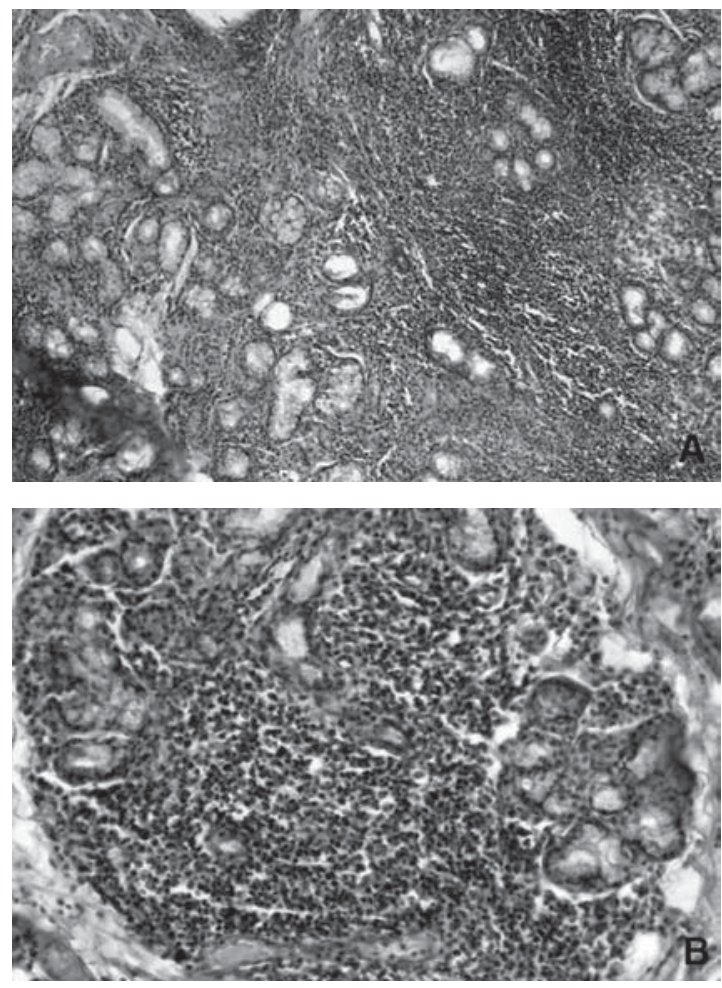

Figura 4. Infiltrado inflamatorio observado en biopsia de glándulas salivales menores.

estos resultados la paciente fue diagnosticada con Síndrome de Sjögren, razón por la cual fue remitida al Servicio de Reumatología del Hospital Central de Maracaibo. De igual forma, como parte del plan de tratamiento la paciente fue referida al Servicio de Odontopediatría para recibir atención odontológica, debido a las múltiples caries.

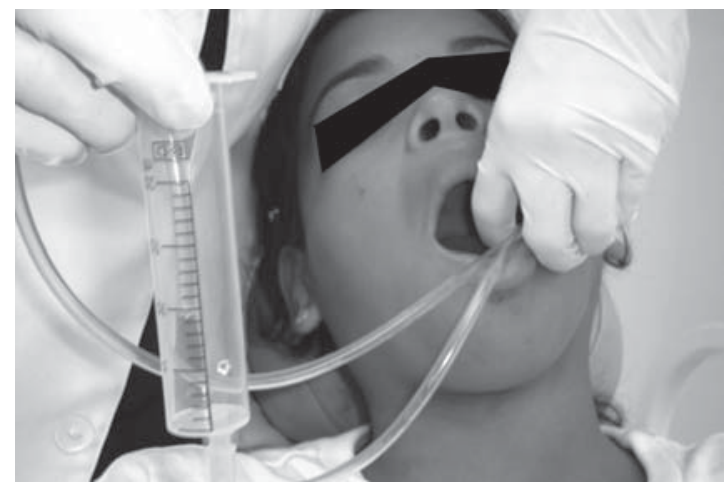

Figura 5. Sialometría parotídea. 


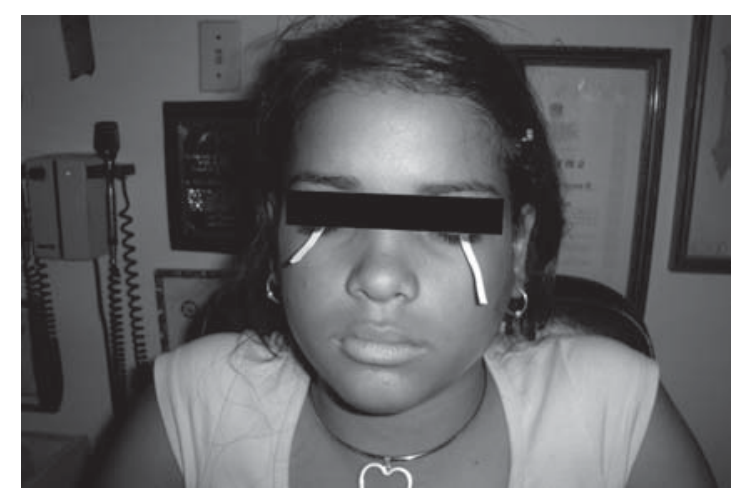

Figura 6. Test de Schirmer.

\section{Discusión}

El SS es una enfermedad autoinmune que afecta más frecuentemente a mujeres entre la cuarta y la quinta década de la vida y es bastante infrecuente en niños y adolescentes ${ }^{12,14,15,17}$, por otra parte, la PCR es una enfermedad inflamatoria crónica que afecta a niños en edades comprendidas entre 4 meses y 15 años y no tiene predilección por el sexo ${ }^{1,2,4,7-9}$, evidenciándose en nuestro caso clínico una mayor relación según sexo y edad para la PCR que para el SS.

Algunas evidencias encontradas en este caso y reportadas en ambas patologías ${ }^{7,11,22}$, como la presencia de episodios inflamatorios recurrentes de la glándula parótida y hallazgos ecográficos que mostraron un proceso inflamatorio inespecífico tipo sialectasia globulosa a nivel de la glándula, dificultaron el diagnóstico definitivo en este caso, además de la ausencia de xerostomía y xeroftalmia. La ausencia de estos dos últimos signos en los estadíos iniciales de la enfermedad o un desarrollo tardío de los mismos, pudiera ser considerada una condición usual en pacientes adolescentes con SS Primario Juvenil ${ }^{12,23,24}$.

De los exámenes indicados, el estudio histopatológico de glándulas salivales menores concuerda con lo reportado por Ussmuller ${ }^{26} \mathrm{y}$ Stiller ${ }^{15}$, quienes sugieren que el infiltrado inflamatorio abundante presente en estas glándulas, es una característica típica del síndrome de Sjögren, por otra parte, hallazgos histológicos encontrados en pacientes diagnosticados con
PCR, después de un período de seguimiento de aproximadamente 7 años, evidenciaron evolución hacia el $\mathrm{SS}^{26}$. La presencia de múltiples episodios de inflamación parotídea bilateral que respaldaron el diagnóstico tentativo de PCR, pudiera estar apoyado en el modelo de la patogénesis del SS presentado por Al-Hashimi ${ }^{10}$, el cual consiste en un proceso de dos fases, una fase inmune y una no inmune. En la fase no inmune, una anomalía genética o una infección, podría producir apoptosis acelerada de las células epiteliales de la glándula; las cuales podrían actuar como autoantígenos, desencadenando una respuesta inmune contra los productos de las células muertas. En la segunda fase o inmune, este proceso inflamatorio inmuno-mediado dañaría las glándulas diana u otros órganos. $\mathrm{La}$ ausencia de una historia familiar positiva para SS no concuerda con el criterio presentado por Al-Hashimi ${ }^{10}$, quien sugiere una posible predisposición genética para el referido síndrome. Sin embargo, características referidas al sexo y la serología positiva para Citomegalovirus encontradas en nuestro paciente, pudieran apoyar la información referida a un posible rol de las hormonas sexuales y la presencia de algún tipo de virus en la patogénesis del $\mathrm{SS}^{10}$. Se ha reportado una limitación en la aplicabilidad de los criterios diagnósticos en edades tempranas ${ }^{12,14,15}$. Sin embargo, probablemente debido a la edad de la paciente, los resultados obtenidos en los estudios complementarios permitieron la aplicación de los criterios establecidos por la American-European Consensus Group.

En pacientes niños y adolescentes con PCR en los cuales a pesar del tratamiento indicado no se logre prolongar el tiempo entre las recurrencias ni disminuir el aumento de tamaño de la glándula satisfactoriamente, debe ser evaluada la presencia del Síndrome de Sjögren, aún en ausencia de síntomas oculares y bucales.

\section{Referencias}

1.- Bradley P: Pathology and treatment of salivary gland conditions. Head Neck Surg 2006; 24: 304-11.

2.- Peñarrocha $M$, Bonet J, Palomar $N$, Minguez JM: Parotiditis Crónica recidivante de la infancia: A propósito de 61 casos. Med Oral 2000; 5: 359-66. 
3.- Grevers $G$, Ihrler $S$, Dresel $S$, Vogl T: The diagnostic value of nuclear magnetic resonance tomography in Sjögren's disease. Laryngorhinootologie 1992; 71 : 519-24.

4.- Concheiro A, Bellver E, Garrido R, García $S$ : Parotiditis crónica recurrente juvenil. An Esp Pediatr 2000; 53: 418-21.

5.- Landaeta M, Giglio M, Ulloa M, Martínez M, Pinto M: Aspectos clínicos, etiología microbiana y manejo terapéutico de la parotiditis crónica recurrente infantil (PCRI). Rev Chil Pediatr 2003; 7: 269-76.

6.- Stong B, Sipp J, Sobol S: Pediatric parotitis: a 5-year review at a tertiary care pediatric institution. Int $\mathrm{J}$ Pediatr Otorhinolaryngol 2006; 70: 541-4.

7.- Mandel L, Bijoor R: Imaging (Computed Tomography, Magnetic Resonante Imaging, Ultrasound and Sialography) in a case of Recurrent Parotitis in Children. J Oral Maxillofac Surg 2006; 64: 984-8.

8.- Turul T, Türkkani G, Saraç S, Sanal Ö: Juvenil recurrent parotitis and immunodeficiency: Report of two cases. Int J Pediatr Otorhinolaryngol Extra 2007; 2: 125-7.

9.- Baurmash H: Chronic Recurrent Parotitis: A closer look at its origin, diagnosis, and management. J Oral Maxillofac Surg 2004; 62: 1010-8.

10.- Al-Hashimi I: The management of Sjögren's Syndrome in dental practice. JADA 2001; 132: 1409-17.

11.- Sutcliffe N: Sjögren's Syndrome. Medicine 2006; 34 : 476-9.

12.- Nikitakis N, Rivera H, Lariccia C, Papadimitriou J, Sauk J: Primary Sjögren syndrome in childhood: Report of a case and review of the literature. Oral Surg Oral Med Oral Pathol Oral Radiol Endod 2003; 96: 42-7.

13.- Toker E, Yavuz S, Direskeneli H: Anti-Ro/SSA and anti-La/SSB autoantibodies in the tear fluid of patients with Sjögren's syndrome. Br J Ophtalmol 2004; 88 : 384-7.

14.- Marmor D, Pinto A: Recurrent parotid enlargement as an initial manifestation of Sjögren's syndrome in children: A case report. Oral Surg Oral Med Oral Pathol Oral Radiol Endod 2004; 97: 459.
15.- Stiller M, Golder W, Döring E, Biedermann T: Primary and secondary Sjögren's Syndrome in children: A comparative study. Clin Oral Investig 2000; 4: 176-82.

16.- Locht H, Pelck R, Manthorpe R: Clinical manifestations correlated to the prevalence of autoantibodies in a large $(n=321)$ cohort of patients with primary Sjögren's syndrome. A comparison of patients initially diagnosed according to the Copenhagen classification criteria with the American-European consensus criteria. Autoimmun Rev 2005; 4: 276-81.

17.- Daniels T: Sjögren's syndrome: clinical spectrum and current diagnostic controversies. Adv Dent Res 1996; 10: 3-8.

18.- Nablieli O, Bar T, Shacham R, Eliav E, Hecot-Nakar $L$ : Management of chronic recurrent parotitis: Current therapy. J Oral Maxillofac Surg 2004; 62: 1150-5.

19.- Molina V, Morales A, Palma G, Pozo C, Quilodrán J, Rostion $C$ : Diagnóstico diferencial de parotidomegalia unilateral en la infancia. Rev Ped Elec 2006; 3: 1822.

20.- Mandel L, Witek E: Chronic parotitis: Diagnosis and treatment. JADA 2001; 132: 1107-11.

21.- Cimaz R, Casadei A, Rose C, et al: Primary Sjögren syndrome in the paediatric age: a multicentre survey. Eur J Pediatr 2003; 162: 661-5. Epub 2003 Jul 29.

22.- López P, Bermejo A: Síndrome de Sjögren. En: Bagán J, Ceballos A, Bermejo A. Medicina Oral. Barcelona: Editorial Masson, 1995; 305-10.

23.- Shimizu M, Okamura K, Yoshiura K, Ohyama Y, Nakamura S, Kinukawa N: Sonographic diagnostic criteria for screening Sjögren's syndrome. Oral Surg Oral Med Oral Pathol Oral Radiol Endod 2006; 102: 85-93.

24.- Wang S, Zhu X, Zou Z: Subclinical Sjögren's syndrome. Zhongua Kou Qiang Yi Xue Za Zhi 1998; 33: 279-81.

25.- Wang S, Zou Z, Yu S, Zhu J: Recurrent swelling of parotid glands and Sjögren's syndrome. Int J Oral Maxillofac Surg 1993; 22: 362-5.

26.- Ussmüller J, Donath K: Histopathogenesis of chronic sialectic parotitis as precursor of mioepithelial sialadenitis lesion (Sjögren's Syndrome). Laryngorhinootologie 1998; 77: 723-7. 